\title{
The Effectiveness of Acceptance and Commitment Therapy (ACT) on Happiness and Hope of Hamedanian Multiple Sclerosis
}

\section{Patients}

\section{Moloud Moslem Khani (MSc)ㄹ, Mohammad Esmaeel Ebrahimi (PhD)2,*, Ali Sahebi $(\mathbf{P h D})^{3}$}

${ }^{1}$ MSc in clinical psychology, Departmant of psychology, Hamedan Branch, Islamic Azad University, Hamedan, Iran

${ }^{2}$ Assistant Professor, Department of psychology, Faculty of Humanities, Hamedan Branch, Islamic Azad University, Hamedan, Iran

${ }^{3}$ Assistant Professor, William Glaser institue, Sydney, Australia

* Corresponding Author: Mohammad Esmaeel Ebrahimi, Department of psychology, Faculty of Humanities, Hamedan Branch, Islamic Azad University, Hamedan, Iran. Email: drms.ebrahimi@iauh.ac.ir

Received: 09/07/2018

Accepted: 13/02/2019

How to Cite this Article: Moslem Khani M, Ebrahimi ME Sahebi A. The Effectiveness of Acceptance and Commitment Therapy (ACT) on Happiness and Hope of Hamedanian Multiple Sclerosis Patients. Pajouhan Scientific Journal. 2019; 17(2): 15-23. DOI: 10.29252/psj.17.2.15

\section{Abstract}

Background and Objective: Disappointment and loss of happiness in multiple sclerosis patients are important factors in the quality of life and the process of illness. Therefore, an effective treatment to reduce frustration and increase the happiness of these patients is important. Therefore, the present study is aimed at the effect of acceptance- and commitment-based therapy (ACT) on happiness and hope for MS patients in Hamedan.

Materials and Methods: The present study was carried out in a semiexperimental design of 30 patients with multiple sclerosis (MS) in Hamedan who were based on the acquisition of scores 1 lower than the mean on happiness and hope scale from 350 patients with multiple sclerosis. The sampling was available and was divided into two treatment groups based on acceptance and commitment and control. Using a pilotpretest-post-test-control study with a control group, the acceptance and commitment-based therapy group was trained in 8 sessions of 60 minutes, while the control group received no intervention during this period. Both groups were evaluated in the pre-test and post-test using the Schneider and Lopez Hope Questionnaire (1989) and the Happiness Test of Oxford Armil (2001) and the results were analyzed using single-variable covariance analysis.

Results: The research results indicated that acceptance and commitment therapy (ACT) had an impact on the happiness and hope of MS patients in Hamedan. So that acceptance and commitment treatment (ACT) affected $36 \%$ on happiness and $54 \%$ on the hope of MS patients.

Conclusion: The results of the present study showed that in the area of treatment and working with depressed patients who are in crisis, pain, and emotional distress, Acceptance and Commitment Therapy can be efficient and promising due to its nature.

Keywords: Acceptance and Commitment Based Treatment; Happiness; Hope; Multiple Sclerosis 
dof: $10.29252 /$ ps.17.2.15

اثربخشى درمان مبتنى بر پذيرش و تعهد بر شادكامى و اميدوارى بيماران زن مبتلا به مولتيّيل اسكلروزيس

\author{
مولود مسلم خانى'، محمد اسماعيل ابر اهيمى r.**، على صاحبى \\ ' إرشناسى ارشد، كروه روانشناسى، واحد همدان، دانشًاه آزاد اسلامى، همدان، ايران.

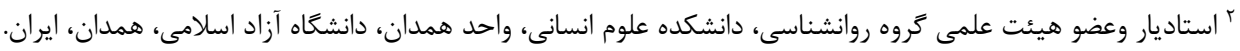 \\ " استاديار، عضو ارشد موسسه ويليام كلاسر، سيدنى، استراليا
} * نويسنده مسئول: محمد اسماعيل ابراهيمى، كروه روانشناسى، دانشكده علوم انسانى، واحد همدان، دانشكاه آزاد اسلامى، همدان، ايران. ايميل: drms.ebrahimi@iauh.ac.ir

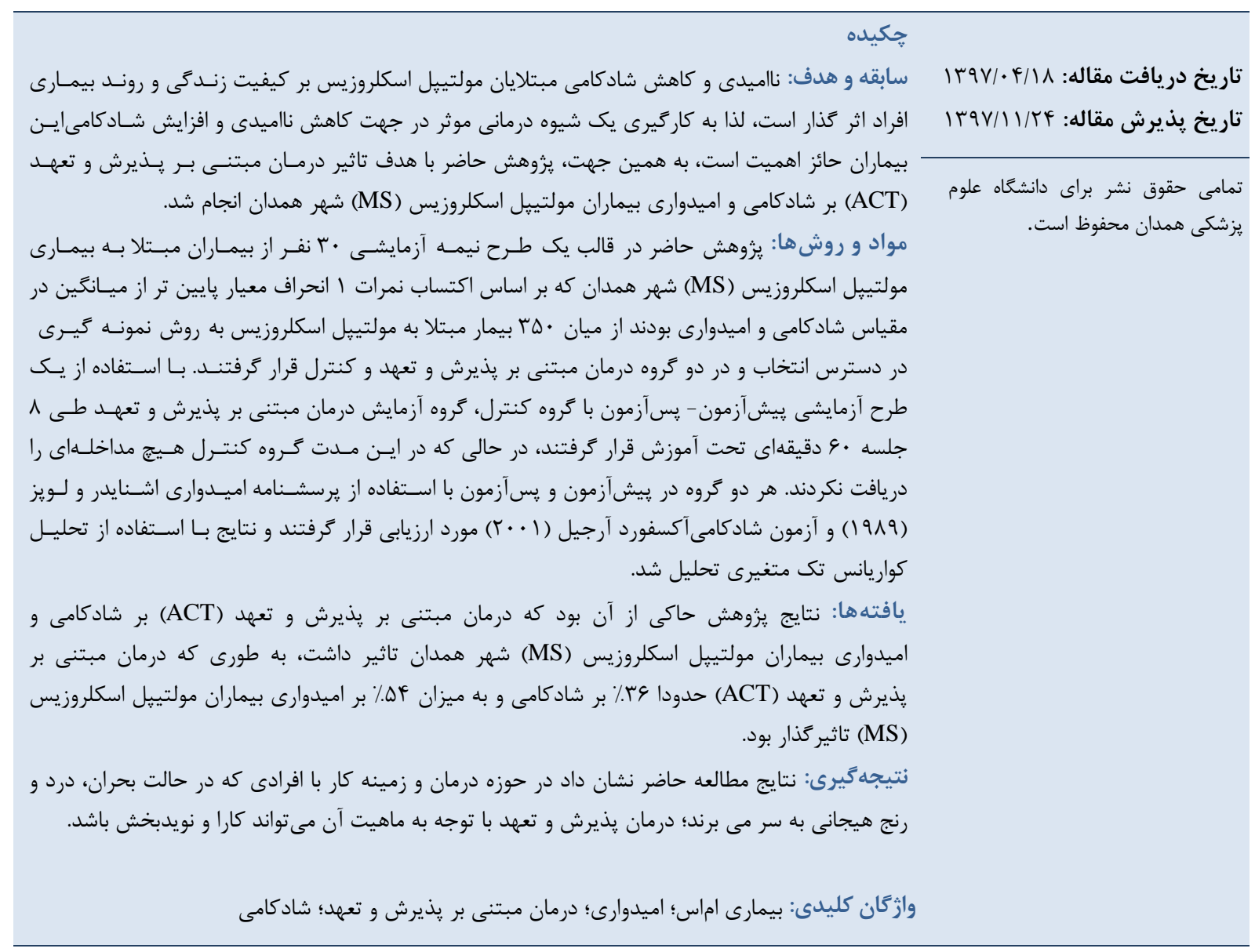

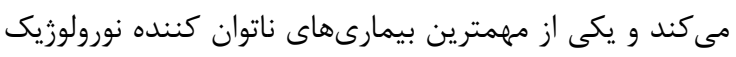

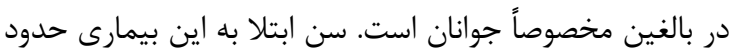

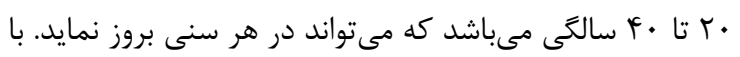

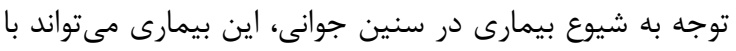

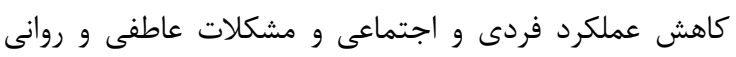

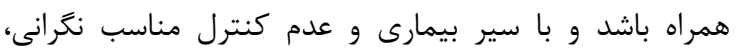

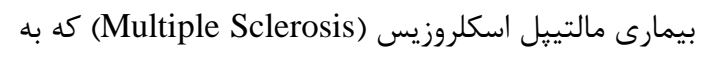

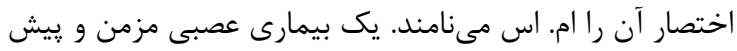

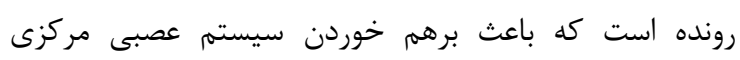

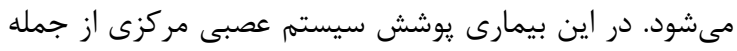

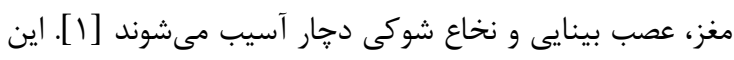

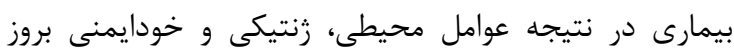


منطقى وجود دارد مبنى بر اينكه درمان مبتنى بر يذيرش و

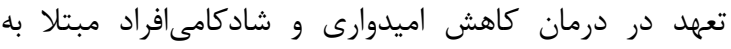
مولتييل اسكلروزيس تاثير مستقيم دارد [ • [1]. شيوه درمانى مبتنى بر يذيرش و تعهد در افرادى كه سخت

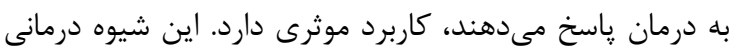

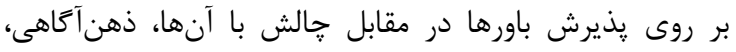

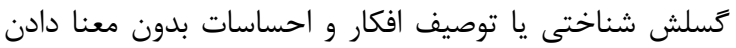

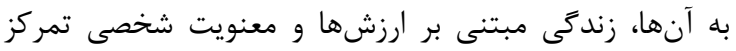

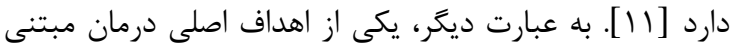

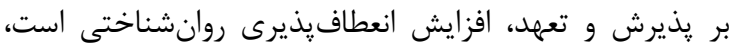

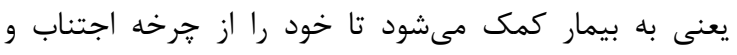

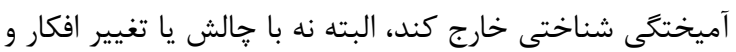

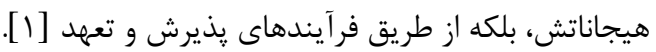

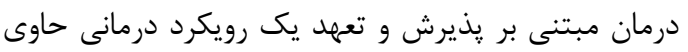

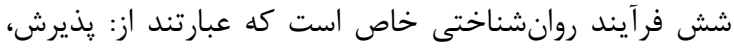

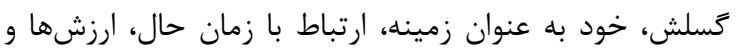

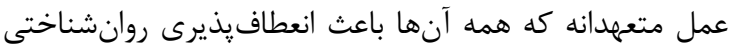

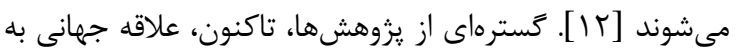

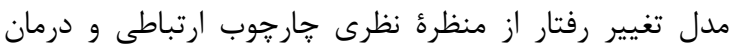

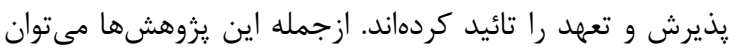

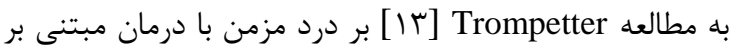

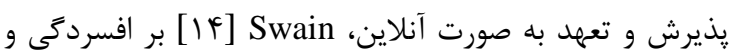

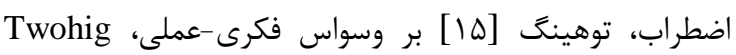

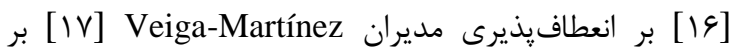
توهمات شنوايى، Eifert و :119 Forsyth

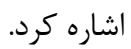
در اين تحقيق، مشكل بيماران ام اس به دو بخش تقسيم

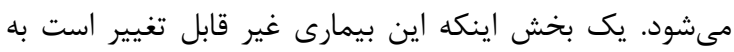

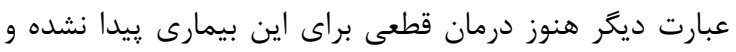

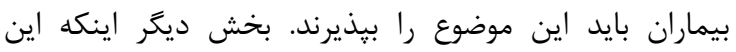

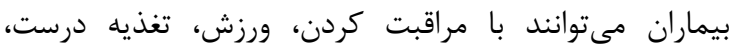

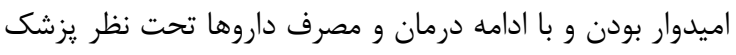
زندگى بهتر و عمر طولانىترى داشته باشند. بنابراين رويكرد

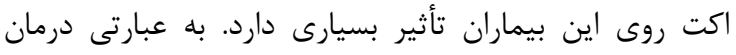

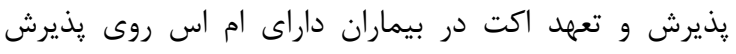

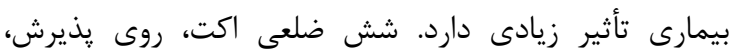
كسلش و در لحظه و حال بودن و در ابعاد ديكر مثل شناخت دادي

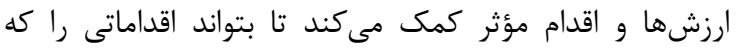

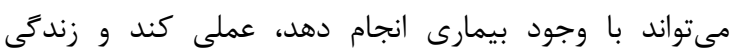

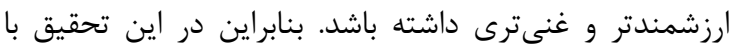

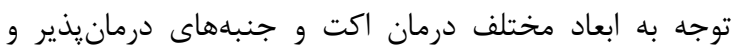

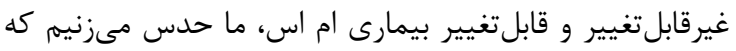

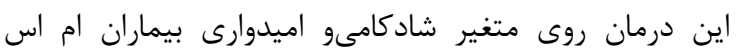

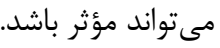

اضطراب و افسردگى را دو جندان كند. آنجه در برخورد با جنينى بيمارى ضرورى به نظر مىرسد يرداختن به مسائل

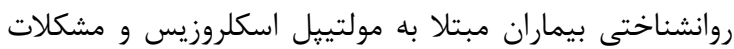
عاطفى است كه بيماران با آن روبرو هستند. بنابراين بيمارى مولئ دئن

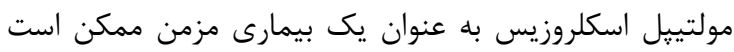

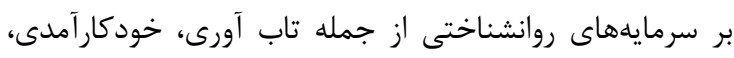

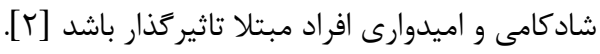

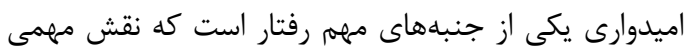

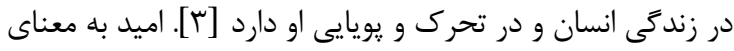

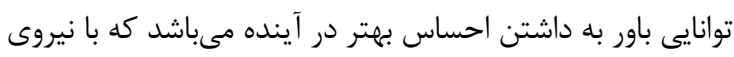

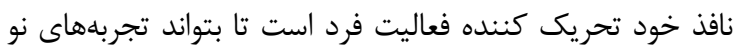

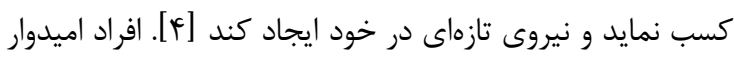

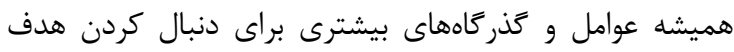

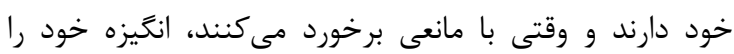

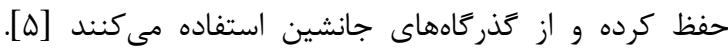

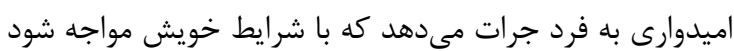

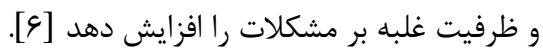

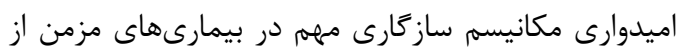
جمله بيمارى مولتييل اسكلروزيس است و به عنوان يك فاكتور

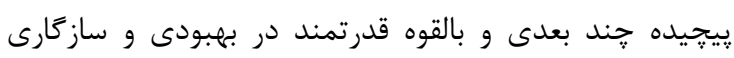

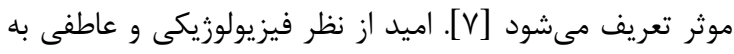

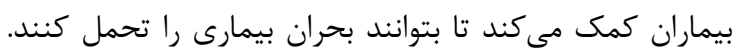

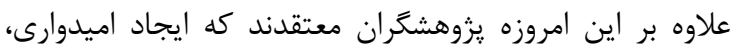

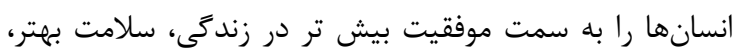

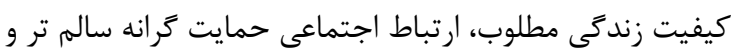

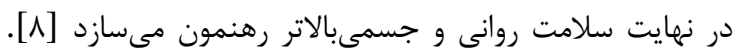
علاوه بر مسئله كاهش سطح اميدوارى در بيماران مبتلا به به ديه

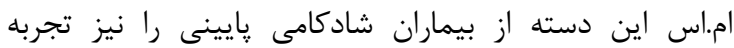

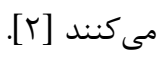

شادكامى از اجزاء شناختى، عاطفى، هيجانى و اجتماعى إنى

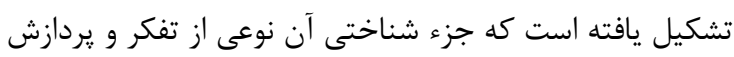

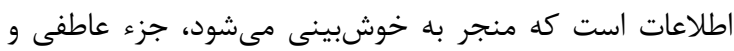

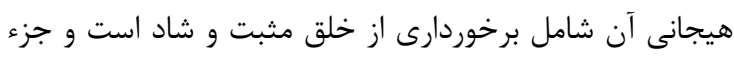

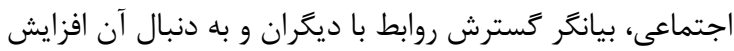

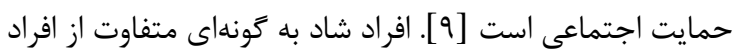

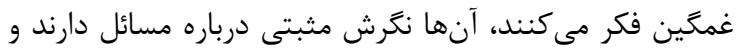

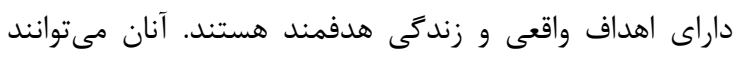

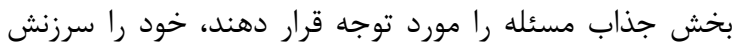

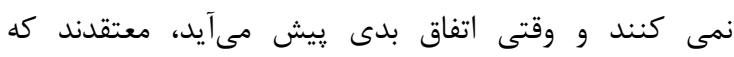

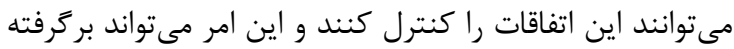
از قدرت شناختى اين افراد باشد. بنابراين با توجه به اين اينكه اينها

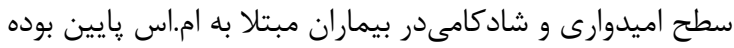

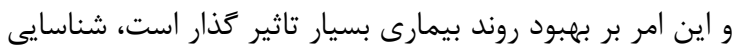

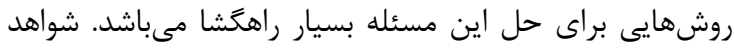


لويز [•r] مشتمل بر r| إ ماده است. بازه نمرات در اين

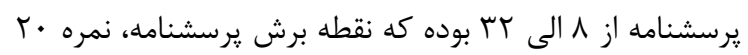

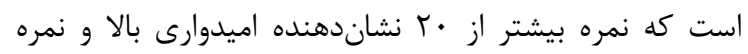

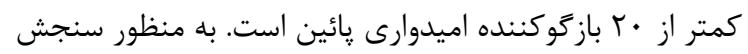

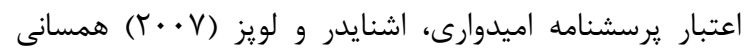

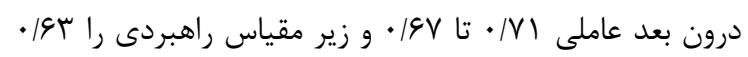

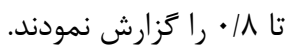

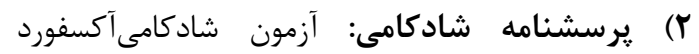

ماراى 9 (Oxford Happiness Questionnaire (OHQ))

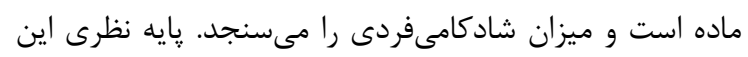

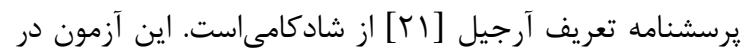

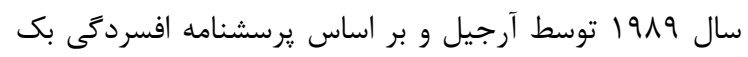

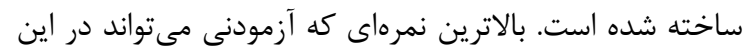

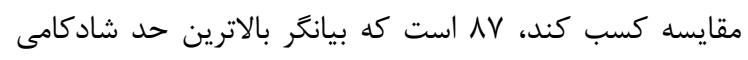

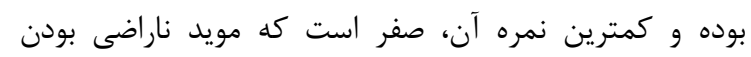

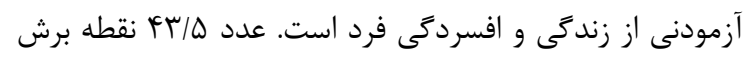

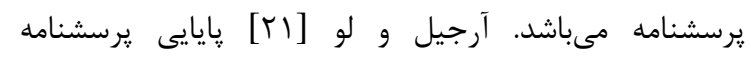

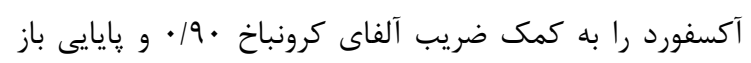

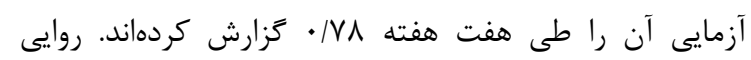

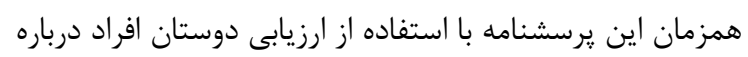

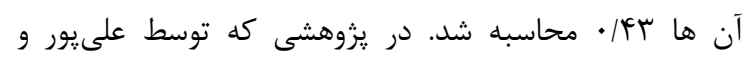

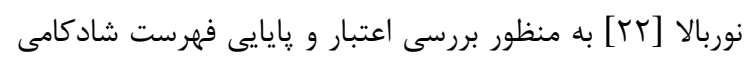

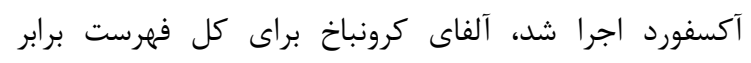

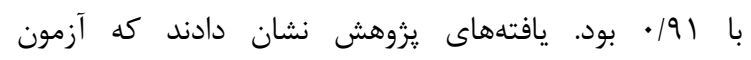

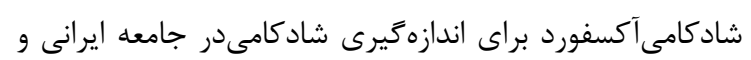
يإيايى مناسب برخوردار است.

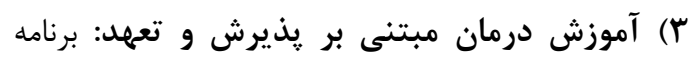

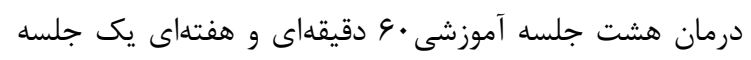

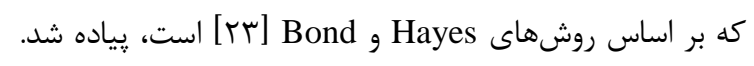

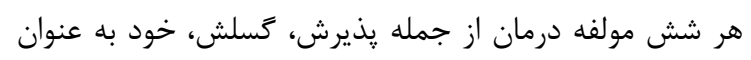

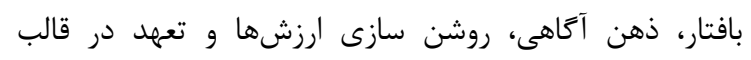

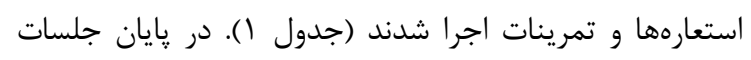

با عنايت به آنجه كَفته شد و نكاهى به آمار ميزان ابتلا به

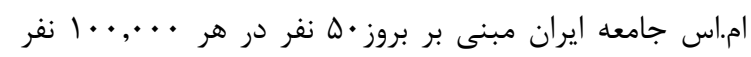

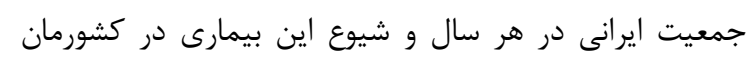

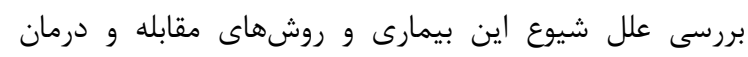

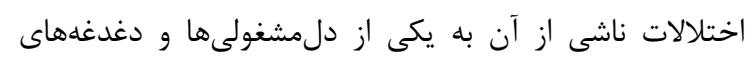

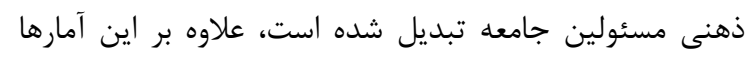

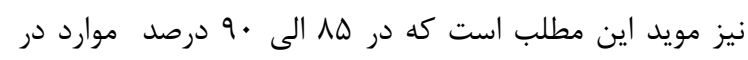

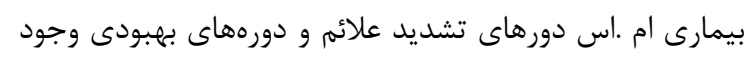

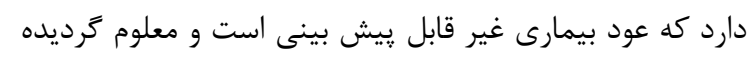

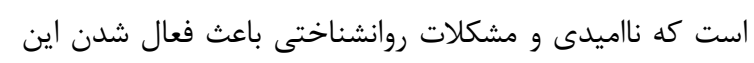

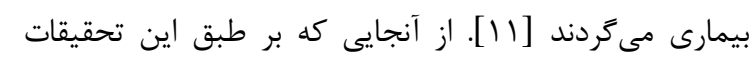

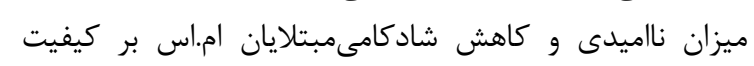

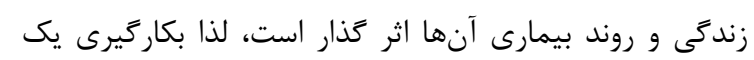

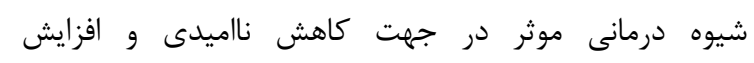

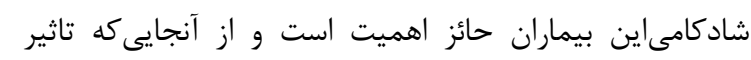

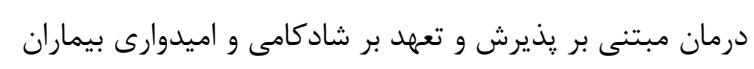

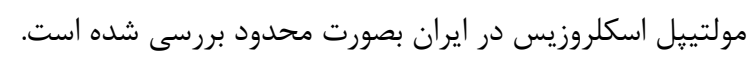

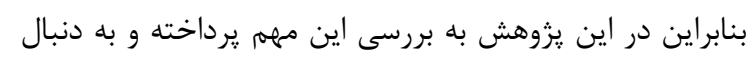

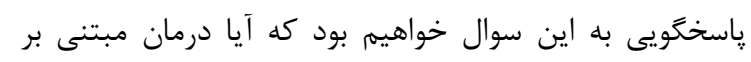

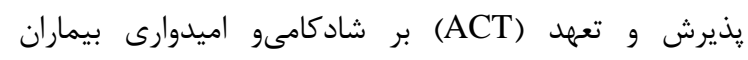
مولتييل اسكلروزيس (MS) شهر همدان تاثير دارد؟ شرى

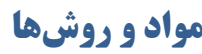

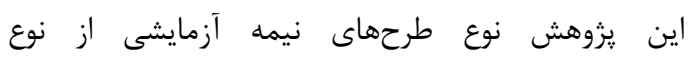

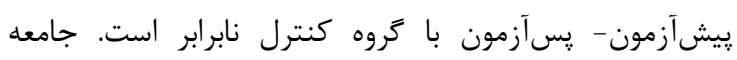

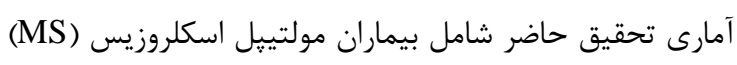

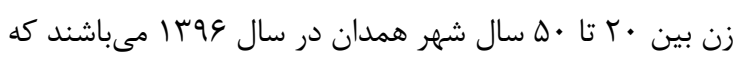

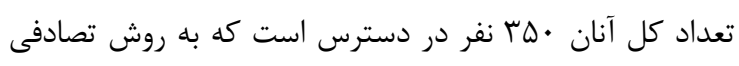

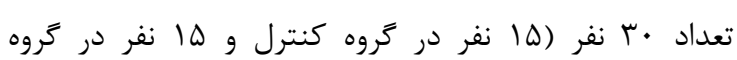

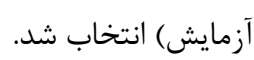

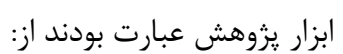

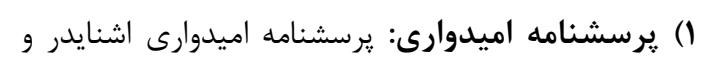

جدول ا: شرح كامل جلسات درمان مبتنى بر يذيرش و وتعهد إمبر

\begin{tabular}{|c|c|}
\hline ميزان موثر بودن آنها و ناميدى سازنده - استعاره خاره، استعاره تشييع جنازه، يا تولد •ـ سالكَى، تمرين بيدا كردن بيلحه & هـ اول \\
\hline 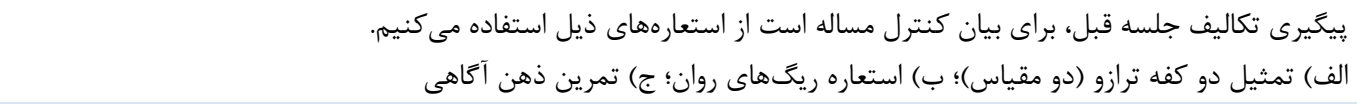 & حلسه د \\
\hline 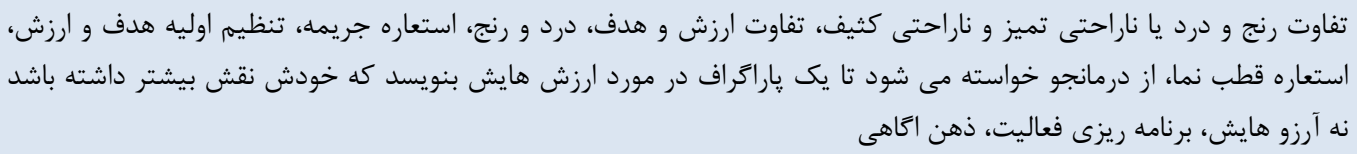 & جلسه سوم \\
\hline 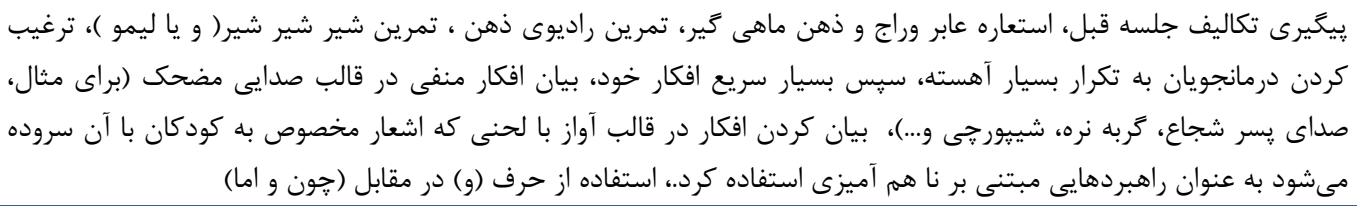 & م \\
\hline
\end{tabular}


ادامه جدول ا.

هدف دراين جلسه معرفى تمايز خود مفهوم سازى شده در برابر خود مشاهدهر است. يّيخيرى تمرينات و تمرين برگها بر روى الف)تمرين مشاهده كر: توجه مراجع و ديدن اشيا در اتاق، در اينجا دو جيز وجود دارد خودتان و كسى كه مشغول نعاه كرد كردن نهر آب آبم

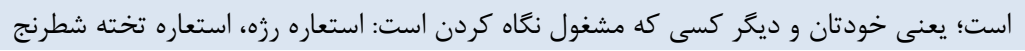

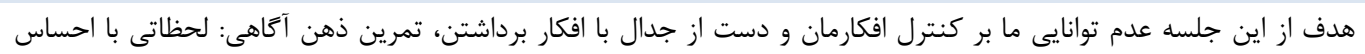

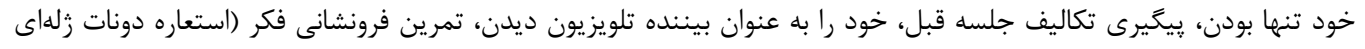

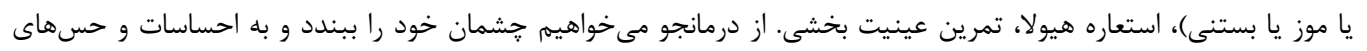

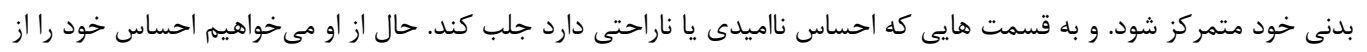
خود جدا كند.

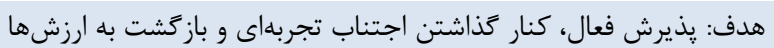

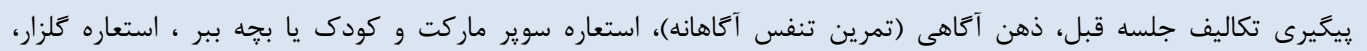

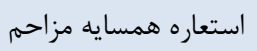

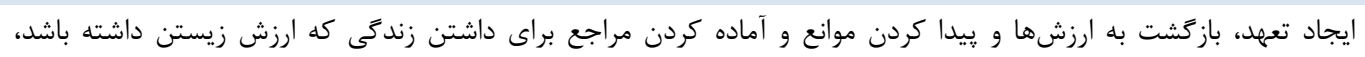

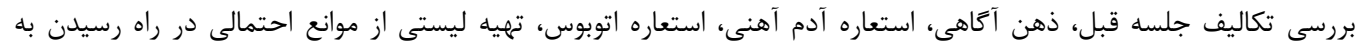

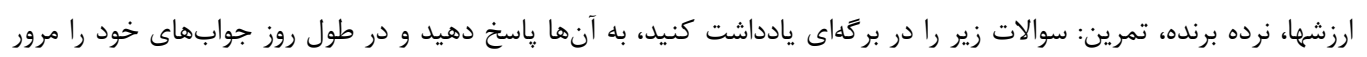

شادكامى و اميدوارى) به صورت اختصار آورده شده است و

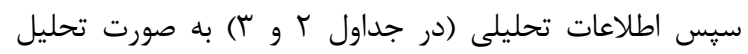
كوواريانس در متغيرها صورت كرفت.

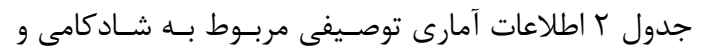

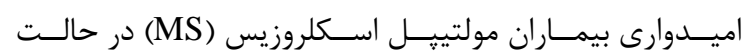

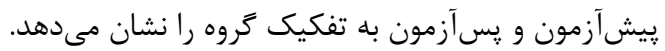

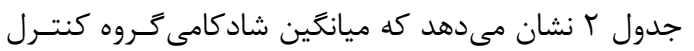

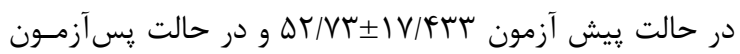

تكاليفى مرتبط با آن جلسه به شركت كنندهها داده شد و در

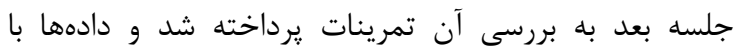

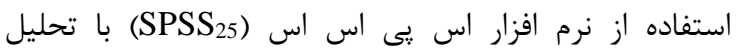
كواريانس تكى متغيرى تحليل شدند.

\section{بافْته}

يافتههاى يزوهش در دو بخش نشان داده شدند. ابتدا

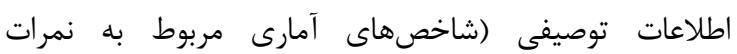

جدول r: شاخصهاى آمارى مربوط به نمرات شادكامى و اميدوارى

\begin{tabular}{|c|c|c|c|c|c|c|c|c|}
\hline بيشتر ين & كمترين & واريانس & انحر افمعيار & ميانگين & تعداد & \multicolumn{2}{|c|}{ تروه } & متغير ها \\
\hline VV & rA & $r \cdot r / q T F$ & TH/VT & $\Delta T / V T$ & 10 & ييش آزمون & \multirow{2}{*}{ كنترل } & \multirow{4}{*}{ شاد كامى } \\
\hline vq & rV & $r \cdot q / 1 / f$ & $|V| \Delta \Lambda \mid$ & $\Delta T / G$ & 10 & يس آزمون & & \\
\hline VT & r. & $r \Delta Y / \Delta V)$ & ID/A9T & $\Delta r$ & 10 & ييش آزمون & \multirow{2}{*}{ آزمايش } & \\
\hline Ve & rT & TTK/.GV & $|Q| \cdot 9 \Lambda$ & $\Delta \Delta / \cdot \varphi$ & 10 & يس آزمون & & \\
\hline$r$. & $r$. & $1 \cdot / 4 Y q$ & T/Yrq & TD & 10 & پيش آزمون & \multirow{2}{*}{ كنترل } & \multirow{4}{*}{ اميدوارى } \\
\hline r & 11 & $|r / V A|$ & $r / \Delta V \Delta$ & $r F / q r$ & 10 & ֶس آزمون & & \\
\hline$r$. & rI & $1 \cdot / r \Delta V$ & $r / r \cdot r$ & $r \Delta / \mathcal{F}$ & 10 & يِش آزمون & \multirow{2}{*}{ آزمايش } & \\
\hline Tr & Tr & $N / 1 / f$ & T/AFA & TN/F & 10 & يس آزمون & & \\
\hline
\end{tabular}

جدول بّ: تحليل كوواريانس تاثير درمان مبتنى بر يذيرش و تعهد (ACT) بر شادكامىدر بيماران مولتييل اسكلروزيس (MS)

\begin{tabular}{|c|c|c|c|c|c|c|}
\hline مجذور اتا & سطح معنى دارى & آماره F & ميانكَين مربعات & درجه آزادى & مجموع مربعات & \\
\hline.$/ 91 \mathrm{r}$ & $\cdot 1 \cdot \cdot 1$ & $V T I / V \cdot r$ & TV.VIGVG & r & $V F I Q / T \Delta R$ & مدل تصحيح شده \\
\hline$\cdot / 1 \mu \wedge$ & $\cdot 1 \cdot \mathrm{FV}$ & r/TוT & $r I / \wedge \Delta \Delta$ & 1 & $r I / \wedge \Delta \Delta$ & عرض از مبداء \\
\hline.$/ 914$ & $.1 \cdot .1$ & $\mid F \Delta F / T q q$ & $V r \& 9 / V 19$ & 1 & $V$ VYq/VI9 & يِيش آزمون \\
\hline$\cdot / r \Delta V$ &.$/ \cdot \cdot 1$ & $14 / 909$ & VQ/V৭৭ & 1 & $\vee \Delta / \vee ৭ 9$ & تروه \\
\hline- & - & - & $0 / .9 \mathrm{~V}$ & TV & $|r \varepsilon| A \mid F$ & خطا \\
\hline- & - & - & - & $r$. & qfyqu & مجموع \\
\hline- & - & - & - & rq & $V \Delta \Delta T / I G V$ & مجموع تصحيح شده \\
\hline
\end{tabular}


جدول f: تحليل كوواريانس تاثير درمان مبتنى بر يذيرش و تعهد (ACT) بر اميدوارى در بيماران مولتيڤل اسكلروزيس (MS)

\begin{tabular}{|c|c|c|c|c|c|c|}
\hline مجذور اتا & سطح معنى دارى & F آماره F & ميانگين مربعات & درجه آزادى & مجموع مربعات & \\
\hline . / 1 r & $\cdot 1 \cdot \cdot 1$ & V./TFr & $19 \cdot 10 T 4$ & t & $T r I / \cdot \Delta T$ & مدل تصحيح شده \\
\hline.$/ 11 Y$ & $\cdot 1 \cdot v^{9}$ & T/FIr & V/V^৭ & 1 & V/V^৭ & عرض از مبداء \\
\hline$\cdot / \vee \wedge 9$ & $\cdot 1 \cdot \cdot 1$ & $1 \cdot 1 / 19$ & r./911 & 1 & r./911 & ِيش آزمون \\
\hline$\cdot \mid \Delta F$ & $\cdot 1 \cdot \cdot 1$ & MI/G4G & VT/TIV & 1 & VT/TIV & تروه \\
\hline- & - & - & T/TAY & tr & $91 / 8 \mid \Delta$ & خطا \\
\hline- & - & - & - & r. & rivis & مجموع \\
\hline- & - & - & - & rq & rAr/G\&V & مجموع تصحيح شده \\
\hline
\end{tabular}

نقش داشته است. از سوى ديكر از مجذور اتا مىتوان (MS)

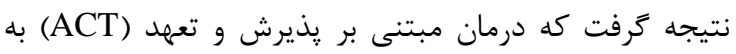

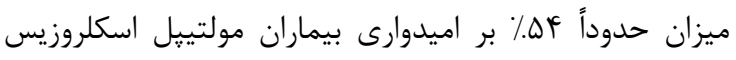
(تأثير كذار است (MS)

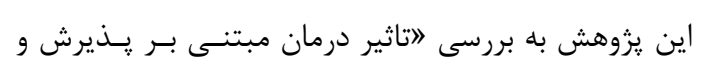

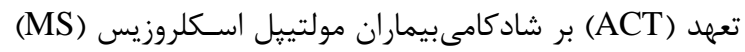

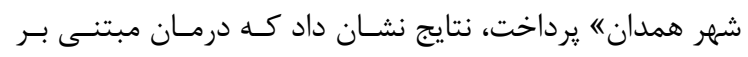

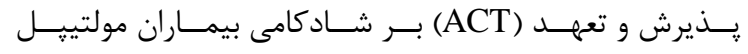

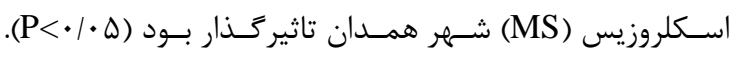

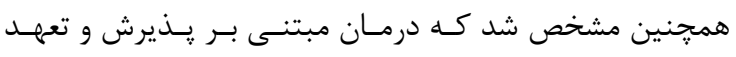

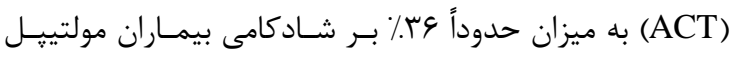

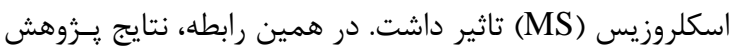

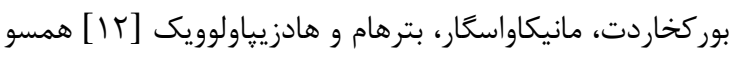

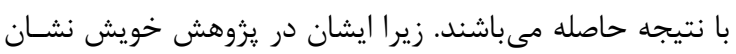

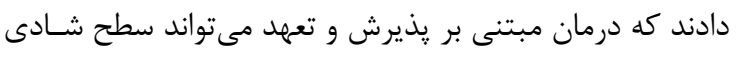

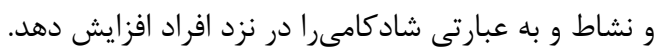

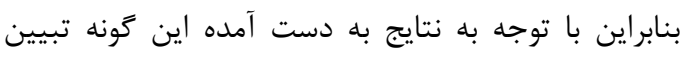

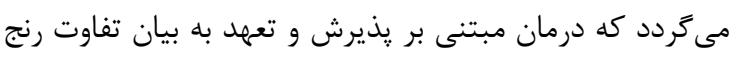

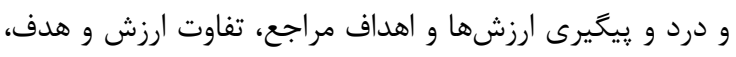

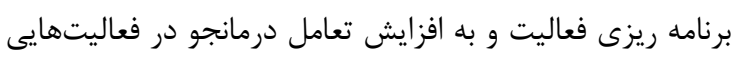

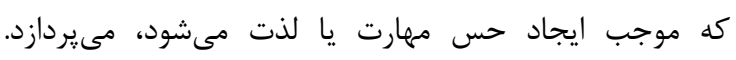

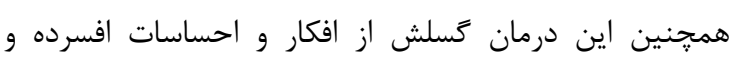

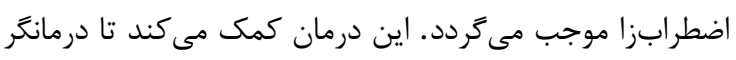

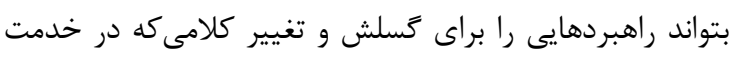

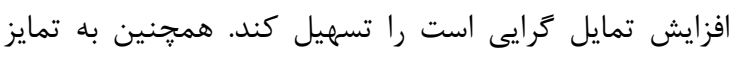

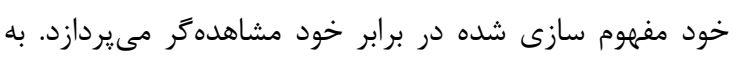

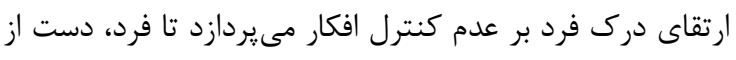

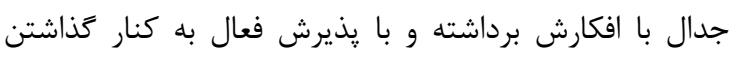

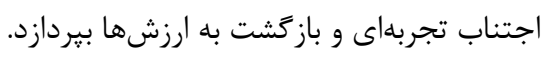

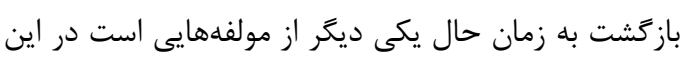

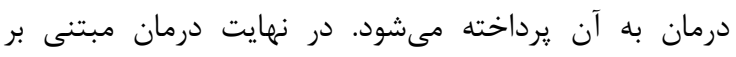

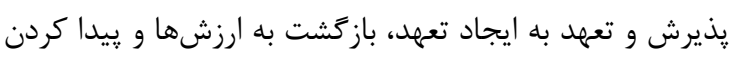

آ

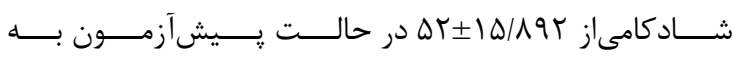

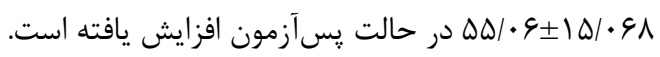

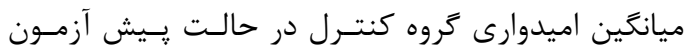
q q q

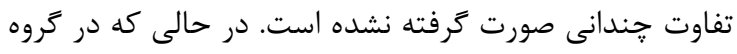

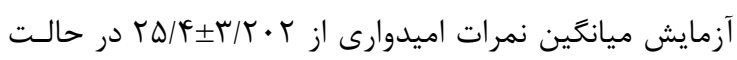

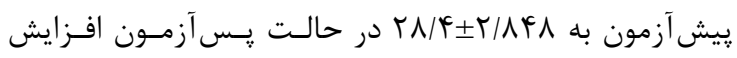
يافته است.

نتايج در بخش اطلاعات تحليلى با استفاده از آزمون تحليل

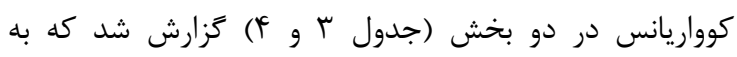

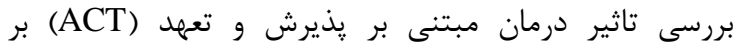

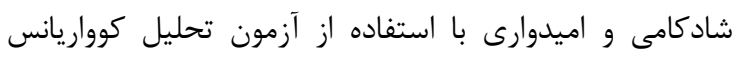
يرداخته شده است.

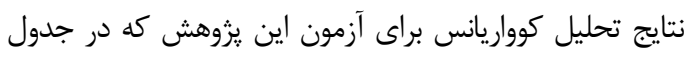

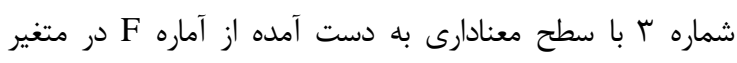

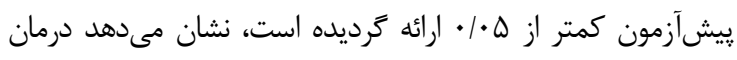

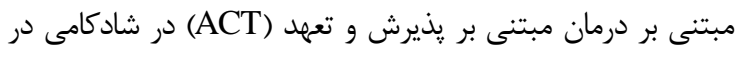

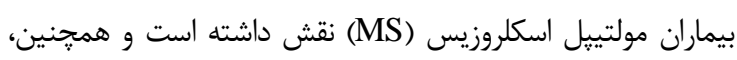

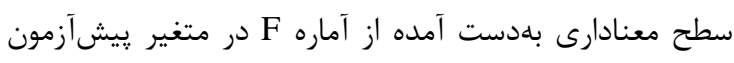

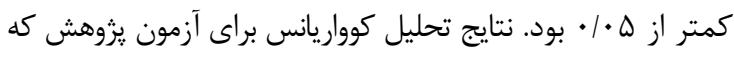

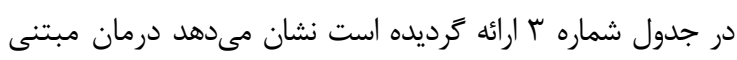

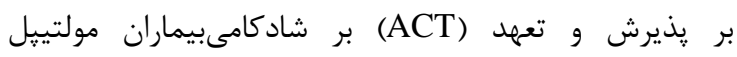

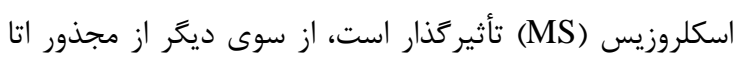

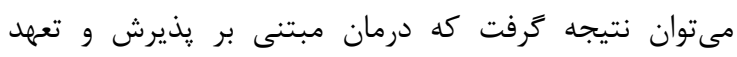

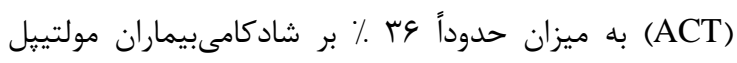

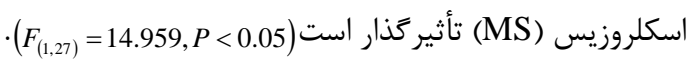

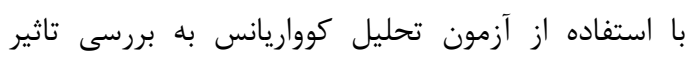

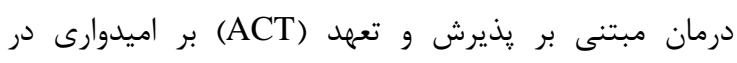

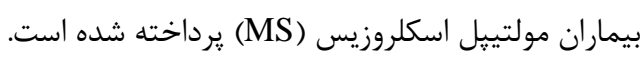

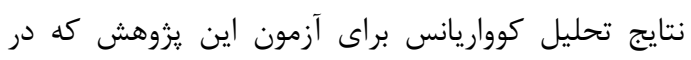

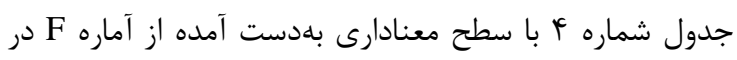

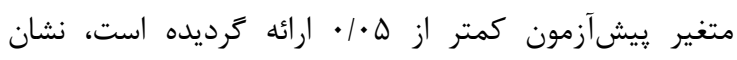

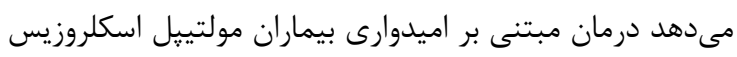


زندكى، انجام كارها بدون وقفه، نداشتن احساس خستگى در طول روز، احساس نيروى زياد براى مقابله با مشكلات روزمره،

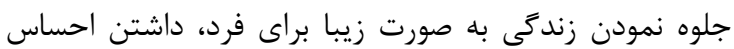
سلامتى و تندرستى، صميمىبودن با ديخران، خوش بين بودن بـن

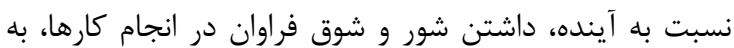

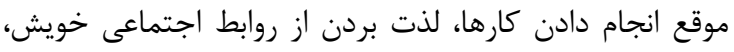

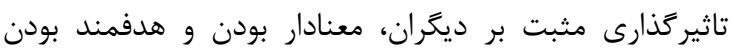
زندگى شخصى، داشتن احساس جذاب بودن و عشق ورزيدن به

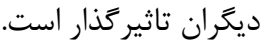

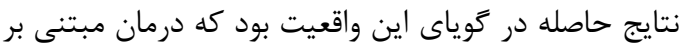

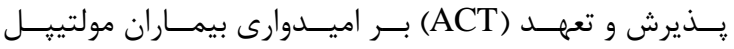

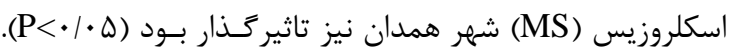

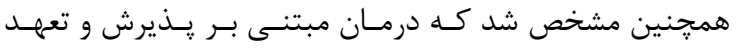

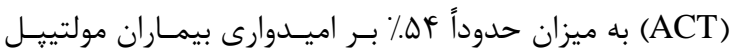

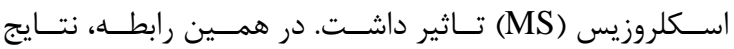

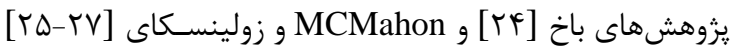

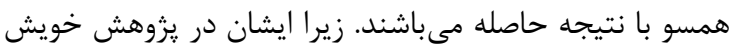

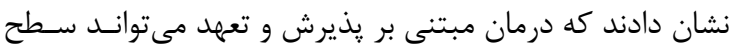

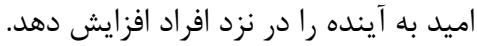

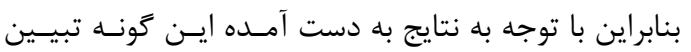

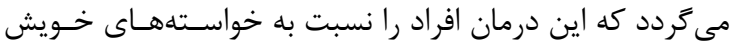

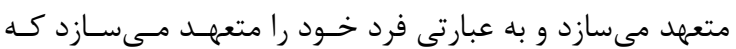
همواره سطح خواستههاى زندگى خويش را افزايش دهد كه كه اين

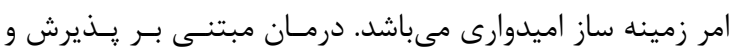

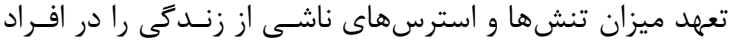

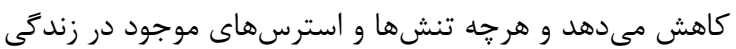

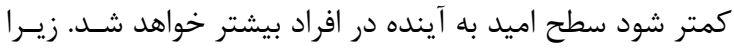

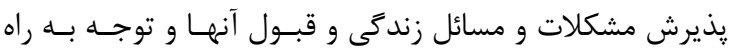

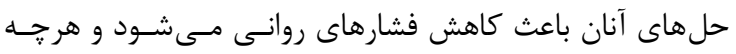

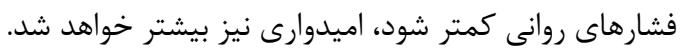

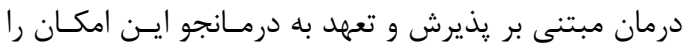

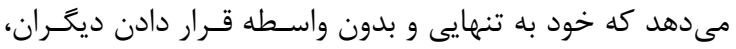

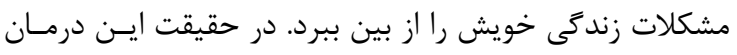

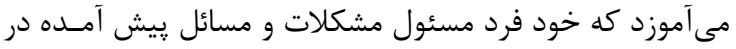

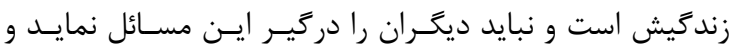
بنابراين همين امر مىتواند اميدوارى را بالا ببرد.

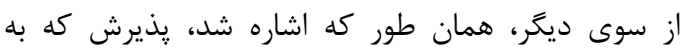
معنى روبرو شدن با مشكلات در مسير رسيدن به ارزشهان

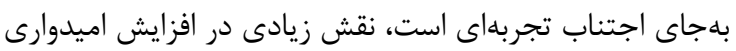
دارد. زيرا با توجه به اينكه شخص بابد دجربه اسيد متعهدانه مشكلات

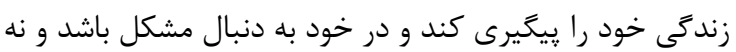
در بين ديكران، همين امر سبب ميىشود كه توانايى مقابله با

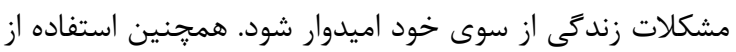

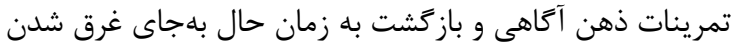

موانع و آماده كردن مراجع براى داشتن زندگى كه ارزش

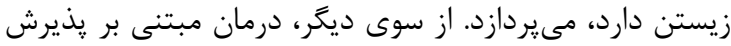

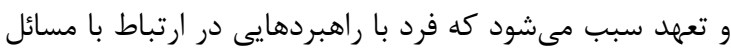

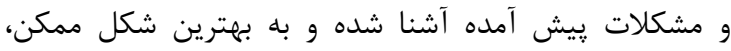

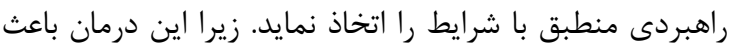

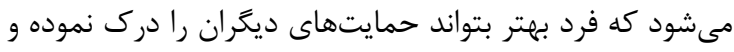

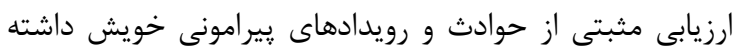

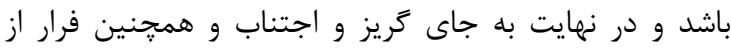

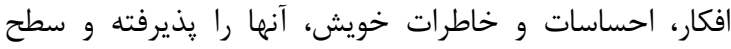
انعطاف يذيرى خويش را افزايش دهد.

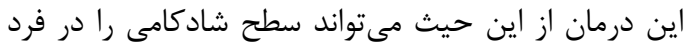

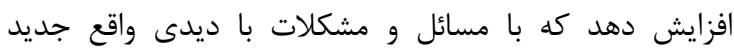

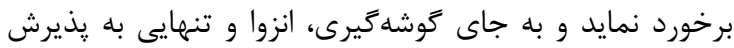

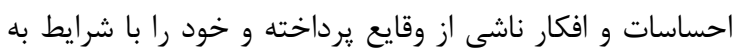

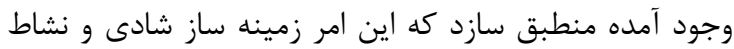

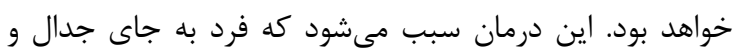

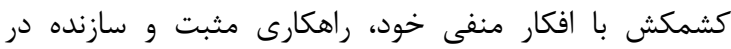

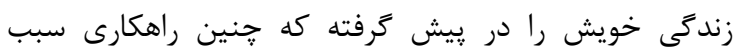

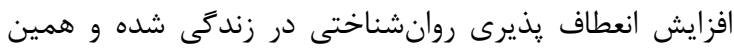
امر زمينه ساز افزايش سطح شادكامى در زندكى مى إنى دود.

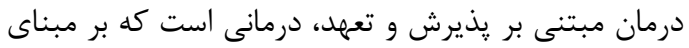

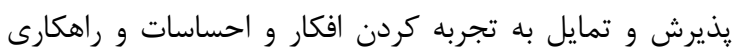

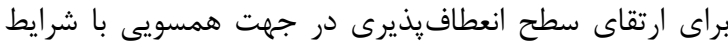

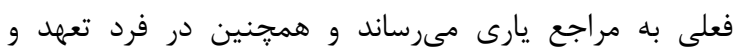

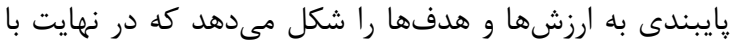
تغيير ارزشهاى زندگى سطح انگيزه و شادى را در خود ارتقاء

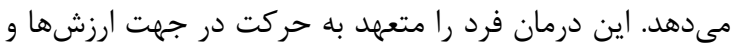

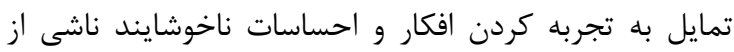

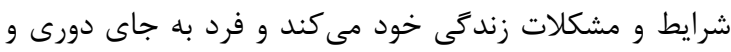
فرار از واقعيت، به مشاهده احساسات و افكار يرداخته و تمايل

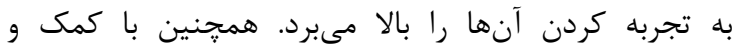

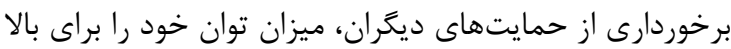

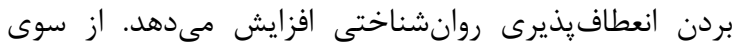

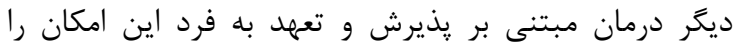
مى دهد كه با راهكارهاى ديخرى براى تمايل افكار و احساسات

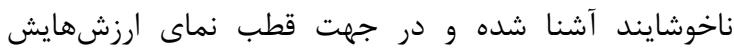

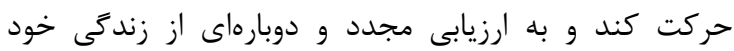

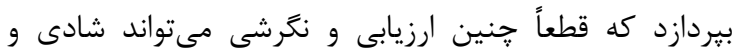
نشاط را براى وى به ارمغان آورد. در كل مىتوان كفت كه درمان مبتنى بر يذيرش ورى ورد تعهد بر

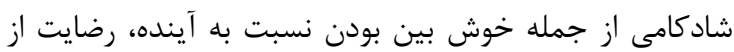

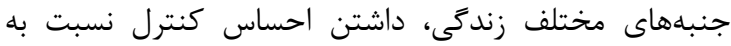

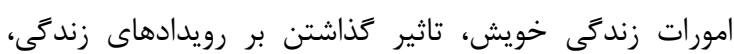

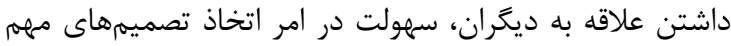




$$
\begin{aligned}
& \text { مقايسه انواع روشهاى درمانى مانند درمان مبتنى بر ذهن }
\end{aligned}
$$

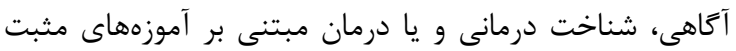

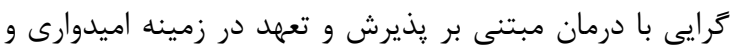

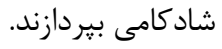

نتيجه تيرى

در كل مىتوان كفت كه درمان مبتنى بر يذيرش و تعهد بر

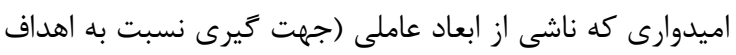

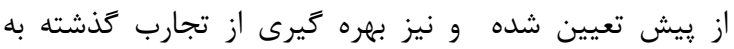

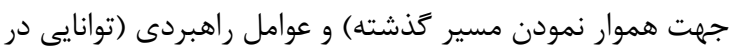

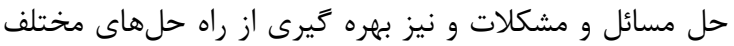
براى مشكلات گوناتون) است، تاثير دارد.

$$
\text { تشكر و قرو فاذى }
$$

اين يزوهش بركرفته از يايان نامه تخصصى كارشناسى ارشد

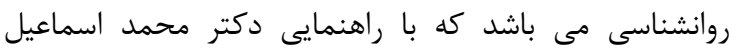

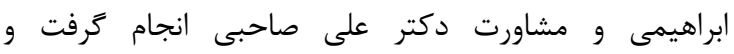

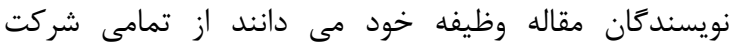
كنندكان در يزوهش كمال قدردانى و تشكر را داشته باشند.

تضاد منافع اين مطالعه براى نويسندَان هيجزَّنه تضاد منافعى نداشته

\section{REFERENCES}

1. Holland NJ, Halper J. Multiple sclerosis: a selfcare guide to wellness. New York: Demos Medical Publishing 2005; 1-10.

2. Brown Felicity L, Whittingham K, Roslyn Boyd N. McKinlay L, Sofronoff Kate. Does Stepping Stones Triple P plus Acceptance and Commitment Therapy improve parent, couple, and family adjustment following paediatric acquired brain injury? A randomised controlled trial. Behaviour Research and Therapy 2007; 73(2015): 58-66.

3. Kenner M, Menon U, Elliott DG. Multiple sclerosis as a painful disease. Int Rev Neurobiol 2007; 79:303-321.

4. Klinger E. Meaning and Void: Inner experience and the incentive in people's lives. Minneapolis: University of Minnesota Press. 2007.

5. Lane RE. The loss of happiness in market democracies. New Haven. CT: Yale University Press. 2013.

6. Myers JE, Harper MC. Evidence- Based effective practices with older adults. Journal of Counseling \& Development 2004; 82(2): 207-18.

7. Hearth K. Enhancing hope in people with a first recurrence. Journal of Advanced Nursing. 2007; 32(6): 1431- 41.

8. Frisch MB. Quality of life therapy. New Jersey: Wiley Press.2006.

9. Lopez SJ. Positive Psychological Assessment: A Handbook of Models and Measures. Washington, DC: American Psychological Associaition.2013.

10. Armstrong K. A History of God. The 4000 year quest of Judaism, Christianity and Islam, New York: Ballantine Books.2013.

11. Buljevac D, Hop WCJ, Reedeker W, Janssens ACJW, Van derMeché F. Van Doorn PA, Hintzen RQ. Self reported stressful life events and exacerbations in multiple sclerosis: prospective study. BMJ. 2013. 327:646.

12. Burckhardt R, Manicavasagar V, Batterham PJ, Hadzi-

$$
\begin{aligned}
& \text { در مقصر قرار دادن ديگران و سير در گذشته و آينده مىتواند بر } \\
& \text { اميدوارى موثر باشد. }
\end{aligned}
$$

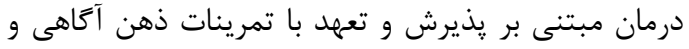

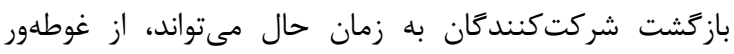

$$
\begin{aligned}
& \text { شدن آنان در كذشته بكاهد و آنها را به آينده اميدوارتر نمان نمايد }
\end{aligned}
$$

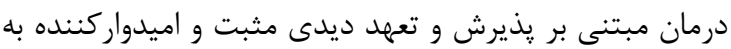

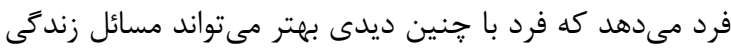

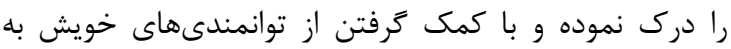

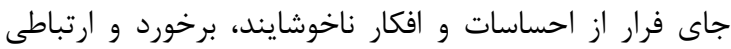

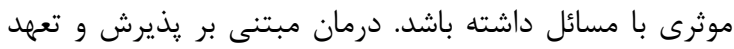

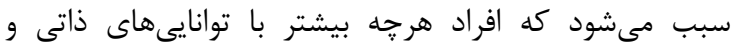

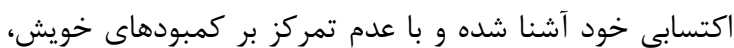

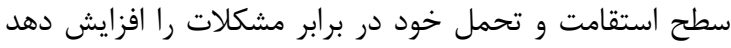

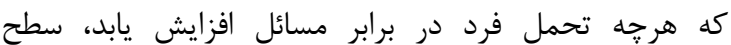

$$
\begin{aligned}
& \text { اميدوارى افزايش مى يابد. } \\
& \text { اين يزوهش مانند ساير يزوهشها مارئ داراى محدوديتهايى }
\end{aligned}
$$

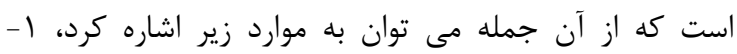

$$
\begin{aligned}
& \text { ناتوانى محقق در كنترل شرايط فرهنكى، اجتماعى و اقتصادى إنى }
\end{aligned}
$$

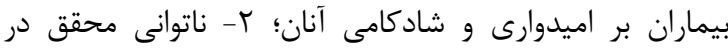

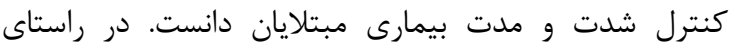

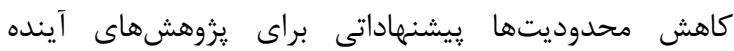

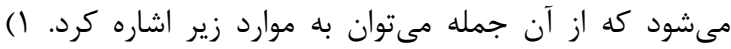

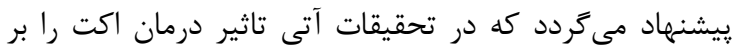

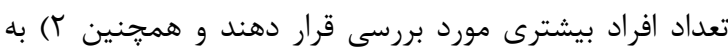

Pavlovic D. A randomized controlled trial of strong minds: A school-based mental health program combining acceptance and commitment therapy and positive. Psychology Journal of School Psychology. 2016; 57:41-52.

13. Trompetter HR, Bohlmeije ET, Fox JP, Schreurs KMG. Psychological flexibility and catastrophizing as associated change mechanisms during online Acceptance \& Commitment Therapy for chronic pain. Behaviour Research and Therapy, 74, 50-59.

14. Swain J, Hancock K, Dixon A, Koo S, Bowman J. Acceptance and Commitment Therapy for anxious children and adolescents: study protocol for a randomized controlled trial. (Retrieved 18 OCT 2015.

15. Twohig Michael P, Whittal Maureen L, Cox Jared M, Gunter Raymond. An initial investigation into the processes of change in ACT, CT, and ERP for OCD. IJBCT.2001; 6(1): 67-83.

16. Moran Daniel J, Consulting P. Using Acceptance and Commitment Training to Develop Crisis-Resilient Change Managers. IJBCT. 2010; 6(4): 341-355.

17. Veiga-Martínez C, Pérez-Álvarez M, García-Montes JM Acceptance and Commitment Therapy Applied to Treatment of Auditory Hallucinations. Clinical Case Studies.2007; 7(2): 118-135.

18. Eifert HG, Forsyth PJ. Acceptance \& Commitment Therapy for anxiety disorders. Oakland: harbinger.2005.

19. Pankey J, Hayes SC. Acceptance and Commitment Therapy for Psychosis. International Journal of Psychology and Psychological Therapy. 2003; 3(2): 311-328.

20. Snyder CR. Hoping. In C. R. Snyder (ed.), coping: The psychology of what works. New York: Oxford University Press. 1999.

21. Argyle M. Personality, self - esteem and demographic 
predictions of happiness and depression. In H. Cheng \& A. Farnham (Eds.), The Psychology of happiness. 2001.

22. Argyle M, L. The psychology of happiness, London: Rutledge.2009.

23. Hayes SC, Bond FW. Act at work. In: Bond F, Dryden W. Editors. Handbook of brief cognitive behavior therapy. West Sussex: John Wiley \& sons' ltd. 2003.

24. Hacker T, Stone P, MacBeth A. Acceptance and commitment therapy - Do we know enough? Cumulative and sequential meta-analyses of andomized controlled trials. Journal of Affective Disorders. 2016; 190(1): 551-565.
25. Bakh A, Compbell L. Happiness and Social Relationships. London: Plenum. 2017.

26. McCallion EA, Zvolensk MJ. Acceptance and commitment Therapy (ACT) for smoking cessation: a synthesis. Cur Opine Psychological. 2015; 2: 47- 51.

27. McCracken L, Vowles K. Acceptance and commitment therapy and mindfulness for chronic pain. American Psychologist. 2015; 69(20): 178-187.

28. MCMahon DM. Happiness-a history: New York, Atlantic Monthly.2016. 